\title{
A Clinical Nomogram for Predicting Cancer-Specific Survival in Pulmonary Large-Cell Neuroendocrine Carcinoma Patients: A Population-Based Study
}

\author{
Haochuan $\mathrm{Ma} \mathbb{D}^{1, *}$ \\ Zhiyong $\mathrm{Xu}^{\mathrm{I}, *}$ \\ Rui Zhou',* \\ Yihong Liu ${ }^{2}$ \\ Yanjuan Zhu ${ }^{\text {I-4 }}$ \\ Xuesong Chang ${ }^{2}$ \\ Yadong Chen ${ }^{2}$ \\ Haibo Zhang ${ }^{\text {-5 }}$ \\ 'The Second Clinical Medical School, \\ Guangzhou University of Chinese \\ Medicine, Guangzhou, People's Republic of \\ China; ${ }^{2}$ Department of Oncology, The \\ Second Affiliated Hospital of Guangzhou \\ University of Chinese Medicine, \\ Guangdong Provincial Hospital of \\ Traditional Chinese Medicine, Guangzhou, \\ People's Republic of China; ${ }^{3}$ Guangdong- \\ Hong Kong-Macau Joint Laboratory on \\ Chinese Medicine and Immune Disease \\ Research, Guangzhou University of \\ Chinese Medicine, Guangzhou, People's \\ Republic of China; ${ }^{4}$ Guangdong Provincial \\ Key Laboratory of Clinical Research on \\ Traditional Chinese Medicine Syndrome, \\ Guangzhou, People's Republic of China; \\ ${ }^{5}$ State Key Laboratory of Dampness \\ Syndrome of Chinese Medicine, The \\ Second Affiliated Hospital of Guangzhou \\ University of Chinese Medicine, \\ Guangzhou, People's Republic of China
}

*These authors contributed equally to this work

Correspondence: Haibo Zhang Department of Oncology, Guangdong Provincial Hospital of Traditional Chinese Medicine, No. II I, Dade Road,

Guangzhou, Guangdong, 510120, People's Republic of China

Tel +86-20-8I 887233

$\mathrm{Fax}+86-20-81874903$

Email haibozh@gzucm.edu.cn
Purpose: This study was designed to construct and validate a nomogram that was available for predicting cancer-specific survival (CSS) in patients with pulmonary large-cell neuroendocrine carcinoma (LCNEC).

Patients and Methods: Using the US Surveillance, Epidemiology, and End Results (SEER) database, we identified patients pathologically diagnosed as LCNEC from 1975 to 2016. Univariate and multivariate Cox regression was conducted to assess prognostic factors of CSS. A novel nomogram model was constructed and validated by the concordance index (C-index), calibration curves and decision curve analysis (DCA).

Results: A total of 624 LCNEC patients were enrolled. Five prognostic factors for CSS were identified and merged to establish nomograms. In the training and validation cohorts, calibration curves displayed the nomogram predictions are in a good agreement with the actual survival. The C-Index of the training and validation cohorts were both higher than 0.8 , and the DCA results showed that the nomogram has clinical validity and utility.

Conclusion: The proposed nomogram resulted in accurate CSS prognostic prediction for patients with LCNEC.

Keywords: pulmonary large-cell neuroendocrine carcinoma, prognosis, nomogram, SEER database, cancer-specific survival

\section{Introduction}

Lung cancer is the most ubiquitous tumors in adults, which ranks second in incidence and first in mortality rate according to estimation from the International Agency for Research on Cancer in 2020. ${ }^{1}$ Pulmonary large-cell neuroendocrine carcinoma (LCNEC) is a rare but highly aggressive neuroendocrine tumor subtype and comprises approximately $3 \%$ of lung cancers. ${ }^{2-4}$

Surgery, radiotherapy and chemotherapy are a common treatment for LCNEC $;^{5,6}$ however, controversy still surrounds standard treatment. In addition, there are currently few large clinical studies available which specifically focus on the treatment, survival, and prognostic factors associated with LCNEC because of low incidence and difficult diagnosis. Therefore, constructing a new predictive model for cancer-specific survival (CSS) in LCNEC is of great significance. One of the most widely available prediction tools is nomogram, a visualizing survival prediction model. ${ }^{7-10}$ Recent studies have developed a nomogram to predict the overall survival (OS) for LCNEC. ${ }^{11}$ However, as far as we are aware, nomograms for predicting the CSS of patients with LCNEC have not been reported. 
Here, the purpose of our study was to formulate comprehensive nomograms based on complete clinical data extracted from the Surveillance, Epidemiology, and End Results (SEER) database to assess CSS at 1 year, 3 years and 5 years in LCNEC patients meeting screening criteria.

\section{Materials and Methods}

\section{Data Source}

The data of this study come from the SEER database and collected by using the software SEER*Stat version 8.3.9, SEER 18 Regs Custom Data [1975-2016] (with additional treatment fields) of the National Cancer Institute (NCI) (account ID: 13538-Nov 2020).

\section{Selection Criteria}

In detail, we collected information on LCNEC patients in 1975-2016 from the SEER database. The inclusion site code was C34-Bronchus and lung, which including C34.0 - Main bronchus; C34.1 - Upper lobe, lung; C34.2 - Middle lobe, lung; C34.3 - Lower lobe, lung; C34.8 - Overlapping lesion of lung; and C34.9 - Lung, NOS. The histological code was 8013/3 - Large cell neuroendocrine carcinoma, following a standard with the International Classification of Tumor Diseases, Third Edition (ICD-O-3).

Patients were included if they satisfied the inclusion criteria: (1) patients were diagnosed with non-small cell lung carcinoma(NSCLC); and (2) patients with pathologically confirmed LCNEC.

The following criteria were used for data exclusion: (1) patients whose tumor characteristics were multi-source or non-primary; (2) patients with incomplete information about histopathologic grading and AJCC stage; and (3) the data on follow-up time and cancer-specific survival are incomplete.

\section{Variables and Main Outcomes}

Nineteen variables have been included in this study, including age $(\leq 49,50-59,60-74$, and $\geq 75)$, race (white, black, and other races), gender (male or female), primary site (main bronchus, upper lobe, middle lobe, lower lobe, overlapping lesion of the lung, and lung NOS), grade (highly differentiated, moderately differentiation, poorly differentiation, and undifferentiated), laterality (left or, right), the 7th edition AJCC staging system (IA, IB, IIA, IIB, IIIA, IIIB, and IV), T stage (T1, T2, T3, T4, and Tx), N stage (N0, N1, N2, N3, and Nx), M stage (M0, M1a, and M1b), surgery (none, laser ablation or cryosurgery, pulmonary lobectomy and pneumonectomy), radiation sequence with surgery (none, intraoperative radiation, radiation after surgery and radiation prior to surgery), radiation (yes or, no/unknown), chemotherapy (yes or, no/unknown), lymph nodes positive (negative/unknown or, positive), bone metastasis (yes or, no), brain metastasis (yes or, no), liver metastasis (yes or, no) and tumor size $(\leq 30,31-50,51-70$, and $>70)$. The main outcome was CSS.

\section{Statistical Analyses}

For nomogram construction and validation, the included patients were randomly divided into training and validation cohorts at a 7:3 ratio in the "sample" function of $R$ version 4.1.0 (http://www.r-project.org/). ${ }^{12,13}$ In the training cohort, univariate analysis was performed using "survival" package for initial screening to select useful predictive features for predicting CSS. ${ }^{14}$ Additional R packages, including "rms", "VIM", "pec", "randomForestSRC" and "foreign" were also used. ${ }^{15}$ The results with $\mathrm{P}<0.05$ in univariate analyses were then further merged into a Cox multivariate regression analysis. We then constructed a nomogram for predicting 1-year, 3-year, and 5-year CSS in LCNEC patients using these identified prognostic factors.

The nomogram model was validated in both training and validation cohorts by the concordance index (C-Index), the calibration curves and decision curve analysis (DCA). The C-Index values were used to assess the predictive accuracy and ranged from 0.5 to 1.0 , with low accuracy (0.5-0.7), moderate accuracy (0.7-0.9), and high accuracy $(>0.9) .{ }^{16}$ We drew calibration curve by bootstrap method (re-sample the data 1000 times) to describes how close predicted probabilities and actual outcomes are. Given its clinical accuracy, practicability and effectiveness, DCA was used to predictive the clinical usefulness and benefits of nomogram model. ${ }^{17}$ The flow chart of study procedures is illustrated in Figure 1. SPSS (Version 26.0 for Windows) and $\mathrm{R}$ software version 4.1.0 were used for statistical all analysis. $\mathrm{P}<0.05$ was considered statistically significant (two-tailed).

\section{Results}

\section{Patient Characteristics}

For this study, we included 624 patients with LCNEC from the SEER database, comprising the training cohort $(\mathrm{n}=$ $436)$ and the validation cohort $(n=188)$. LCNEC are more prevalent among older populations (52.6\% of patients were aged between 60 years and 74 years). Most of the primary sites were upper lobe $(60.9 \%)$, the majority of 


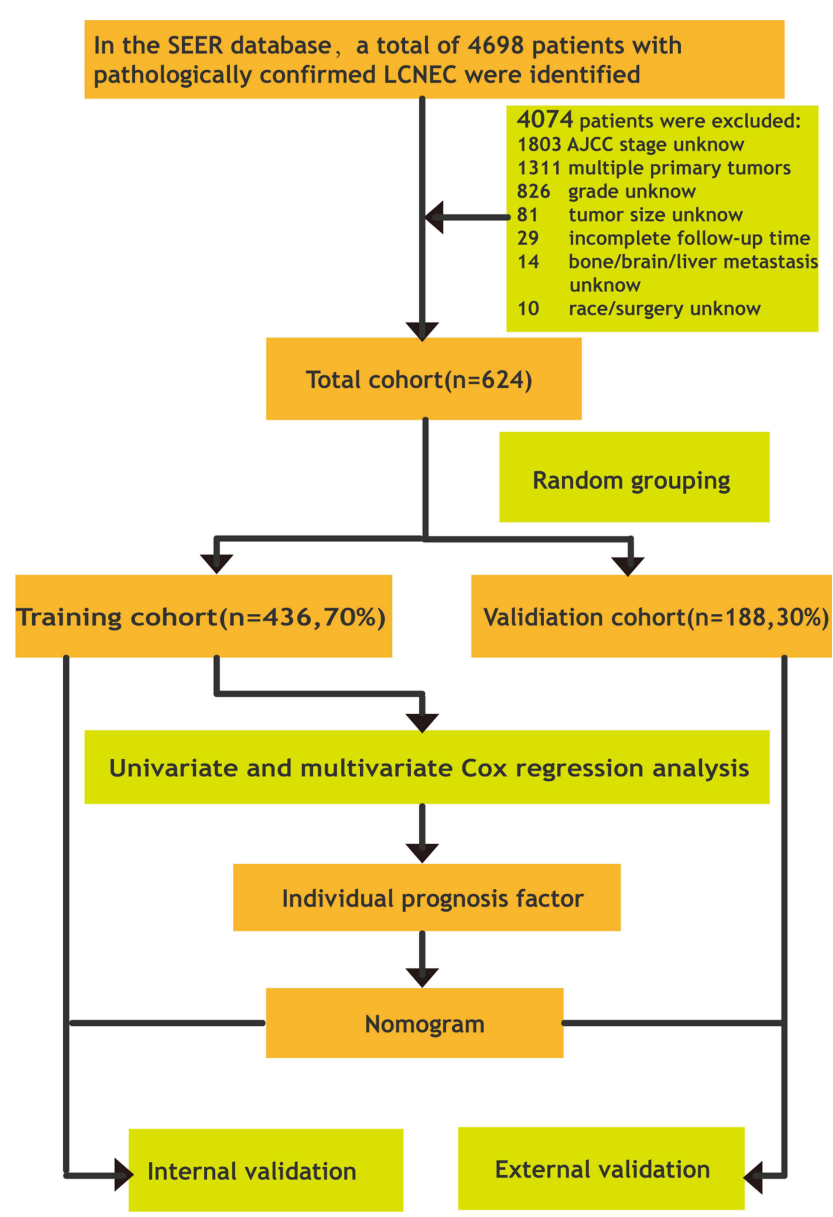

Figure I Flow chart of study procedures.

patients with AJCC stage IV (34.9\%), and the most histological grade was G3 (73.2\%). 52.4\% of the patients received surgery, $36.5 \%$ of the patients received radiotherapy, and $53.8 \%$ of the patients received chemotherapy. Characteristics of the both cohorts are summarized in Table 1.

\section{CSS Curves Stratified by Different}

\section{Factors}

Demonstrated in Figure 2A, females have a better prognosis than males $(\mathrm{P}<0.01)$. The CSS curve also revealed that LCNEC patients with tumors originating in main bronchus had a worse CSS outcome compared with those primary tumors in the upper or lower lobes (Figure 2B). The survival outcomes of LCNEC patients are even worse when the disease develops into more advanced AJCC stages, T stages, $\mathrm{N}$ stages, $\mathrm{M}$ stages and greater number of positive lymph nodes (Figures $2 \mathrm{C}-\mathrm{G}$ ). In addition, larger tumor size is proportional to the worse survival outcomes(Figure $2 \mathrm{H}$ ).
Table I Patients' Characteristics of Included Patients

\begin{tabular}{|c|c|c|c|}
\hline Variables & $\begin{array}{c}\text { Total } \\
(n=624)\end{array}$ & $\begin{array}{l}\text { Training } \\
\text { Cohort } \\
(n=436)\end{array}$ & $\begin{array}{c}\text { Validation } \\
\text { Cohort } \\
(n=188)\end{array}$ \\
\hline \multicolumn{4}{|l|}{ Age, n(\%) } \\
\hline$\leq 49$ & $38(6.1)$ & $28(6.4)$ & $10(5.3)$ \\
\hline $50-59$ & $144(23.1)$ & $103(23.6)$ & $4 \mid(2 \mid .8)$ \\
\hline $60-74$ & $328(52.6)$ & $229(52.5)$ & $99(52.7)$ \\
\hline$\geq 75$ & $114(18.3)$ & $76(17.4)$ & $38(20.2)$ \\
\hline \multicolumn{4}{|l|}{ Race, n(\%) } \\
\hline White & $525(84.1)$ & $368(84.4)$ & $157(83.5)$ \\
\hline Black & $78(12.5)$ & $53(12.2)$ & $25(\mid 3.3)$ \\
\hline Other races & $21(3.4)$ & 15(3.4) & $6(3.2)$ \\
\hline \multicolumn{4}{|l|}{ Gender, n(\%) } \\
\hline Male & $34 I(54.6)$ & $233(53.4)$ & $108(57.4)$ \\
\hline Female & $283(45.4)$ & $203(46.6)$ & $80(42.6)$ \\
\hline \multicolumn{4}{|l|}{ Primary Site, n(\%) } \\
\hline Main bronchus & $26(4.2)$ & $19(4.4)$ & $7(3.7)$ \\
\hline Upper lobe & $380(60.9)$ & $263(60.3)$ & $117(62.2)$ \\
\hline Middle lobe & $23(3.7)$ & $19(4.4)$ & $4(2.1)$ \\
\hline Lower lobe & $167(26.8)$ & $114(26.1)$ & $53(28.2)$ \\
\hline $\begin{array}{l}\text { Overlapping lesion } \\
\text { of lung }\end{array}$ & $7(1.1)$ & $6(1.4)$ & $\mathrm{I}(0.5)$ \\
\hline Lung, NOS & $21(3.4)$ & $15(3.4)$ & $6(3.2)$ \\
\hline \multicolumn{4}{|l|}{ Grade, n(\%) } \\
\hline I & $6(1.0)$ & $5(I .1)$ & $\mathrm{I}(0.5)$ \\
\hline II & $12(1.9)$ & $9(2.1)$ & $3(1.6)$ \\
\hline III & $457(73.2)$ & $319(73.2)$ & $138(73.4)$ \\
\hline IV & $149(23.9)$ & $103(23.6)$ & $46(24.5)$ \\
\hline \multicolumn{4}{|l|}{ Laterality, n(\%) } \\
\hline Left & $265(42.5)$ & $|8|(4 \mid .5)$ & $84(44.7)$ \\
\hline Right & $359(57.5)$ & $255(58.5)$ & $104(55,3)$ \\
\hline \multicolumn{4}{|l|}{ AJCC Stage, n(\%) } \\
\hline IA & $115(18.4)$ & $82(18.8)$ & $33(17.6)$ \\
\hline IB & $72(11.5)$ & $54(12.4)$ & $18(9.6)$ \\
\hline$\| \mathrm{A}$ & $60(9.6)$ & $42(9.6)$ & $18(9.6)$ \\
\hline IIB & $44(7.1)$ & $28(6.4)$ & $16(8.5)$ \\
\hline IIIA & $89(14.3)$ & $62(14.2)$ & $37(19.7)$ \\
\hline IIIB & $26(4.2)$ & $18(4.1)$ & $8(4,3)$ \\
\hline IV & $218(34.9)$ & $150(34.4)$ & $68(36.2)$ \\
\hline \multicolumn{4}{|l|}{ T stage, $\mathbf{n}(\%)$} \\
\hline TI & $173(27.7)$ & $127(29.1)$ & $46(24.5)$ \\
\hline $\mathrm{T} 2$ & $203(32.5)$ & $139(31.9)$ & $64(34.0)$ \\
\hline T3 & $130(20.8)$ & $92(21.1)$ & $38(20.2)$ \\
\hline $\mathrm{T} 4$ & $110(17.6)$ & $75(17.2)$ & $35(18.6)$ \\
\hline$T x$ & $8(1.3)$ & $3(0.7)$ & $5(2.7)$ \\
\hline \multicolumn{4}{|l|}{ N stage, $n(\%)$} \\
\hline No & $329(52.7)$ & $232(53.2)$ & $97(51.6)$ \\
\hline NI & $84(13.5)$ & $58(\mid 3.3)$ & $26(13.8)$ \\
\hline
\end{tabular}

(Continued) 
Table I (Continued).

\begin{tabular}{|c|c|c|c|}
\hline Variables & $\begin{array}{c}\text { Total } \\
(n=624)\end{array}$ & $\begin{array}{l}\text { Training } \\
\text { Cohort } \\
(n=436)\end{array}$ & $\begin{array}{c}\text { Validation } \\
\text { Cohort } \\
(n=188)\end{array}$ \\
\hline N2 & $161(25.8)$ & $\mathrm{III}(25.5)$ & $50(26.6)$ \\
\hline N3 & $46(7.4)$ & $3 I(7.1)$ & $15(8.0)$ \\
\hline $\mathrm{Nx}$ & $4(0.6)$ & $4(0.9)$ & $0(0)$ \\
\hline \multicolumn{4}{|l|}{ M stage, $n(\%)$} \\
\hline Mo & $406(65.1)$ & $286(65.6)$ & $120(63.8)$ \\
\hline Mla & $37(5.9)$ & $21(4.8)$ & $16(8.5)$ \\
\hline MIb & $|8|(29.0)$ & $129(29.6)$ & $52(27.7)$ \\
\hline \multicolumn{4}{|l|}{ Surgery, n(\%) } \\
\hline None & $297(47.6)$ & $207(47.5)$ & $90(47.9)$ \\
\hline $\begin{array}{l}\text { Laser ablation/ } \\
\text { cryosurgery }\end{array}$ & $\mathrm{I}(0.2)$ & $\mathrm{I}(0.2)$ & $0(0)$ \\
\hline Pulmonary & $310(49.8)$ & $215(43.1)$ & $95(50.5)$ \\
\hline lobectomy & & & \\
\hline Pneumonectomy & $16(2.6)$ & $13(3.0)$ & $3(1.6)$ \\
\hline \multicolumn{4}{|l|}{$\begin{array}{l}\text { Radiation sequence } \\
\text { with surgery, n(\%) }\end{array}$} \\
\hline None & $530(85.0)$ & $376(86.2)$ & I54(81.9) \\
\hline $\begin{array}{l}\text { Intraoperative } \\
\text { radiation }\end{array}$ & $2(0.3)$ & $0(0)$ & $2(1.1)$ \\
\hline $\begin{array}{l}\text { Radiation after } \\
\text { surgery }\end{array}$ & $81(13.0)$ & $52(11.9)$ & $29(15.4)$ \\
\hline $\begin{array}{l}\text { Radiation prior to } \\
\text { surgery }\end{array}$ & $\mathrm{II}(\mathrm{I} .8)$ & $8(1.8)$ & $3(1.6)$ \\
\hline \multicolumn{4}{|l|}{ Radiation, n(\%) } \\
\hline Yes & $228(36.5)$ & $162(37.2)$ & $66(35.1)$ \\
\hline No/unknown & $396(63.5)$ & $274(62.8)$ & $122(64.9)$ \\
\hline \multicolumn{4}{|l|}{ Chemotherapy, n(\%) } \\
\hline Yes & $336(53.8)$ & 234(53.7) & $102(54.3)$ \\
\hline No/unknown & $288(46.2)$ & $202(46.3)$ & $86(45.7)$ \\
\hline \multicolumn{4}{|l|}{ LN Positive, n(\%) } \\
\hline Negative/unknown & $519(83.2)$ & $363(83.3)$ & $156(83)$ \\
\hline Positive & $105(16.8)$ & $73(16.8)$ & $33(17.1)$ \\
\hline \multicolumn{4}{|l|}{$\begin{array}{l}\text { Bone metastasis, } \\
\text { n(\%) }\end{array}$} \\
\hline Yes & $70(11.2)$ & $48(11.0)$ & $22(11.7)$ \\
\hline No & $554(88.8)$ & $388(89.0)$ & $166(88.3)$ \\
\hline \multicolumn{4}{|l|}{$\begin{array}{l}\text { Brain metastasis, } \\
\mathrm{n}(\%)\end{array}$} \\
\hline Yes & $82(13.1)$ & $6 I(14.0)$ & $2 I(I I .2)$ \\
\hline No & $542(86.9)$ & $375(86.0)$ & 167(88.8) \\
\hline \multicolumn{4}{|l|}{$\begin{array}{l}\text { Liver metastasis, } \\
\text { n(\%) }\end{array}$} \\
\hline Yes & $58(9.3)$ & $43(9.9)$ & $15(8.0)$ \\
\hline No & $566(90.7)$ & $393(90.1)$ & $170(92.0)$ \\
\hline
\end{tabular}

(Continued)
Table I (Continued).

\begin{tabular}{|l|c|c|c|}
\hline Variables & $\begin{array}{c}\text { Total } \\
(\mathbf{n}=624)\end{array}$ & $\begin{array}{c}\text { Training } \\
\text { Cohort } \\
(\mathbf{n}=\mathbf{4 3 6})\end{array}$ & $\begin{array}{c}\text { Validation } \\
\text { Cohort } \\
(\mathbf{n}=188)\end{array}$ \\
\hline $\begin{array}{l}\text { Tumor size, } \mathbf{n}(\%) \\
\leq 30\end{array}$ & $249(40.0)$ & $177(40.6)$ & $72(38.3)$ \\
$31-50$ & $170(27.2)$ & $117(26.8)$ & $53(28.2)$ \\
$51-70$ & $90(14.4)$ & $62(14.2)$ & $28(14.9)$ \\
$>70$ & $115(18.4)$ & $80(18.3)$ & $35(18.6)$ \\
\hline
\end{tabular}

Abbreviations: AJCC, American Joint Commission on Cancer; LN, lymph node.

Patients with radiotherapy or chemotherapy had obviously worse survival outcomes(Figure $3 \mathrm{~A}$ and $\mathrm{B}$ ). LCNEC patients without surgery achieved a significantly shorter CSS time than those with surgery $(\mathrm{P}<0.01)$ (Figure 3C). LCNEC patients with bone metastasis, brain metastasis, and liver metastasis had a much worse prognosis (Figures 3D-F).

\section{Screening for Prognostic Factors for LCNEC}

Table 2 shows the results of the univariate and multivariate Cox regression analysis. In univariate Cox analysis, gender, primary site, AJCC stage, T stage, $\mathrm{N}$ stage, M stage, surgery, radiation, chemotherapy, lymph nodes positive, bone metastasis, brain metastasis, liver metastasis, and tumor size were significantly associated with CSS (all $\mathrm{P}<0.001$ except for primary site and chemotherapy, with $\mathrm{P}=0.016$ and $\mathrm{P}=0.003$, respectively). These variables were integrated into multivariate Cox analysis except for $\mathrm{T}$ stage, $\mathrm{N}$ stage, and $\mathrm{M}$ stage, which have mutual influence with AJCC stage into the multivariate analysis. Based on the results, gender, AJCC stage, surgery, chemotherapy, and brain metastasis were identified as independent risk factors for CSS.

\section{Nomogram Construction}

Based on the above prognostic factors, a nomogram to predict 1 year, 3 years and 5 years CSS was created (Figure 4). The nomogram demonstrated that surgery has held the largest contribution to CSS outcomes, followed by AJCC stage, chemotherapy, brain metastasis and gender. Each independent prognostic variables were assigned a score scale; the total score is obtained by adding the scores of each selected variable. In accordance with the patient information, this nomogram can help in estimating 
A

Survival curve of gender $(\mathrm{P}<0.01)$

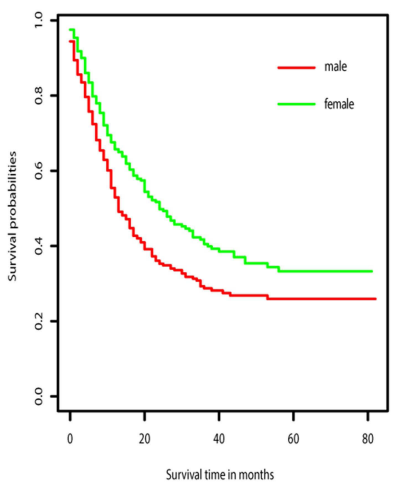

E

Survival curve of $T$ stage $(P<0.01)$

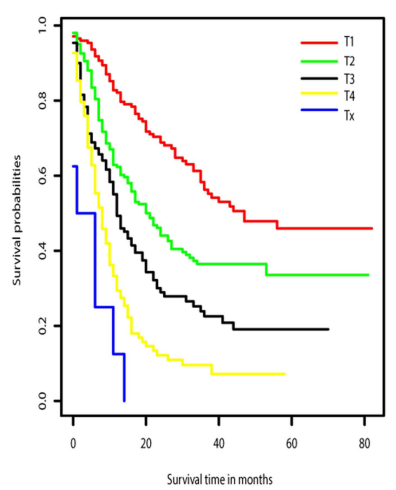

B

Survival curve of primary site $(P<0.01)$
C

Survival curve of AJCC stage $(P<0.01)$
D

Survival curve of $L N$ positive $(P<0.01)$

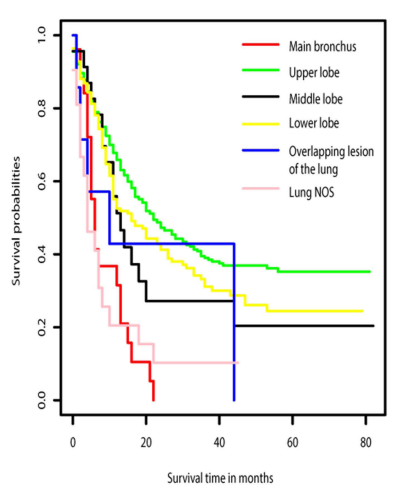

$\mathbf{F}$

Survival curve of $N$ stage $(P<0.01)$

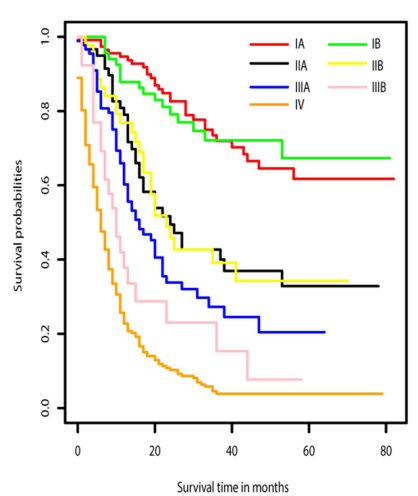

G

Survival curve of $M$ stage $(P<0.01)$

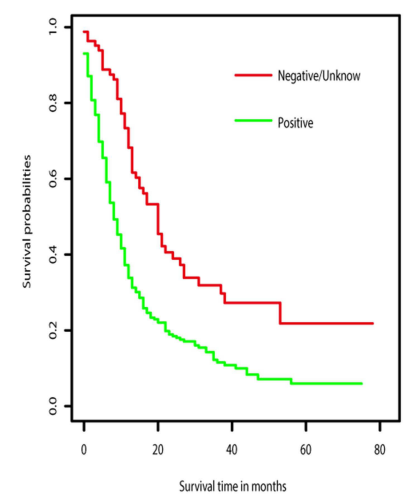

H

Survival curve of Tumor size $(P<0.01)$
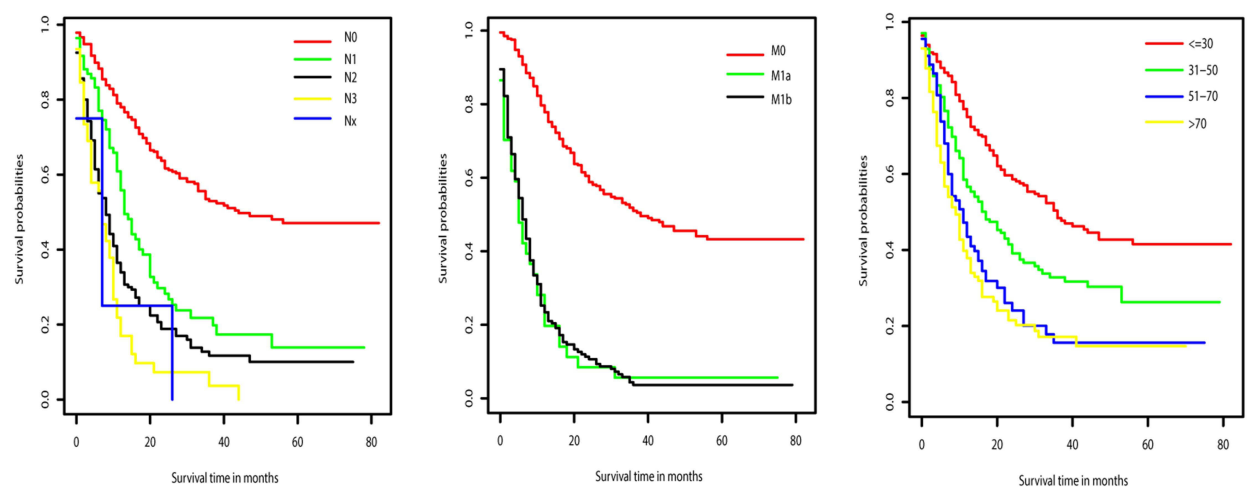

Figure 2 Cancer-specific survival of LCNEC patients stratified by $(\mathbf{A})$ gender; $(\mathbf{B})$ primary site; $(\mathbf{C})$ AJCC stage; (D) LN positive; (E) T stage; (F) N stage; (G) M stage; (H) tumor size.

Abbreviations: LCNEC, pulmonary large-cell neuroendocrine carcinoma; LN, lymph node.

the 1 year, 3 years and 5 years CSS for each individual patient.

\section{Nomogram Validation}

On the basis of nomogram, the $\mathrm{C}$-indices for predicting 1 -year CSS were 0.82 and 0.83 in the training and validation cohorts, respectively (Figure 5). Furthermore, the $\mathrm{C}$-indices of the 3-year CSS and 5-year CSS exceeded 0.77 in both cohorts, demonstrating that the model was reliable. The calibration plots of the nomogram displayed the nomogram predictions are in a good agreement with the actual survival both in the training (Figure 6A) and validation cohorts (Figure 6B) for 1 year, 3 years and 5 years CSS. Moreover, the DCA results showed that the nomogram has clinical validity and utility (Figure 7).

\section{Discussion}

LCNEC is rare form of lung cancer that is not often observed in clinical practice, and there is a dearth of largesample studies regarding the epidemiological and clinical characteristics, and prognosis of LCNEC. Although there are a few of studies focused on the clinicopathological characteristics and survival of LCNEC, many of them still have drawbacks in the selection of the selection criteria and variables. ${ }^{18-22}$ Therefore, the reliable prediction of CSS for LCNEC patients is still a difficult problem. Nomogram, an effective prognosis prediction model, inherit an advantage over traditional AJCC stage. Moreover, there is still a lack of validation in large sample-based using real world data, which are more for evaluating CSS prognosis among patients with LCNEC. Therefore, based on the data of SEER database, with the 
A

Survival curve of radiation $(\mathrm{P}<0.01)$

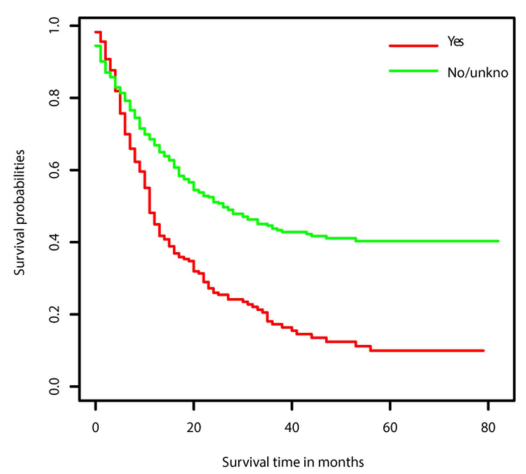

D

Survival curve of bone metastasis $(P<0.01)$
B

Survival curve of chemotherapy $(\mathrm{P}=0.03)$

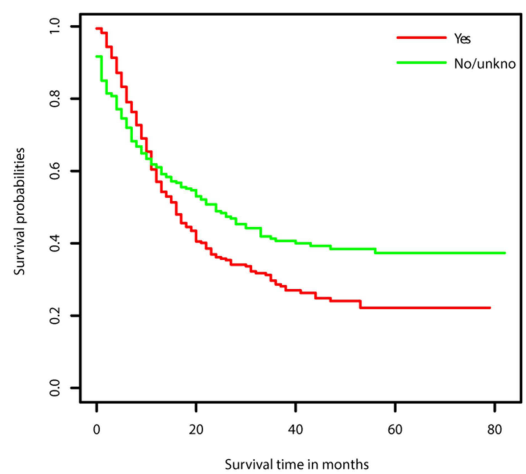

E

Survival curve of brain metastasis $(P<0.01)$
C

Survival curve of surgery $(\mathrm{P}<0.01)$
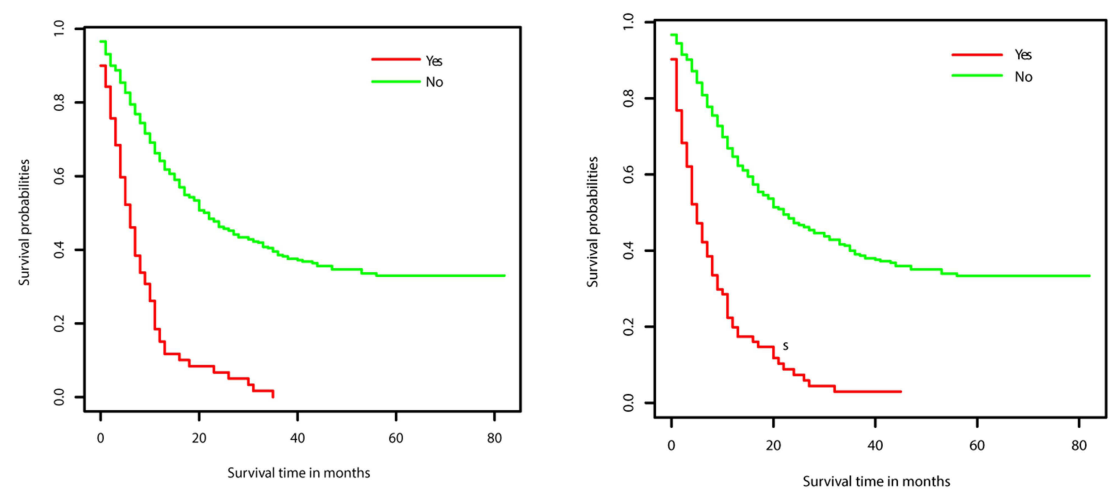

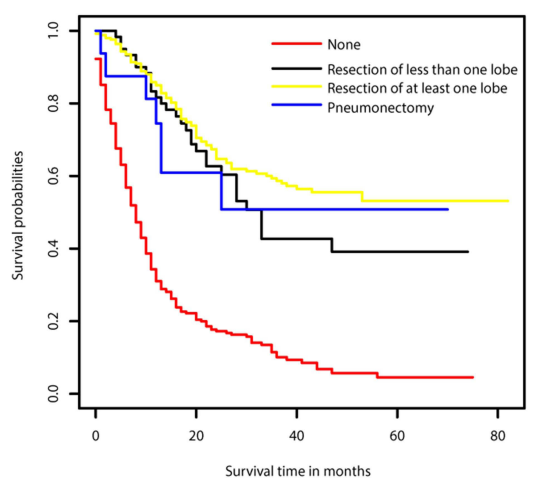

$\mathbf{F}$

Survival curve of liver metastasis $(P<0.01)$

Figure 3 Cancer-specific survival of LCNEC patients stratified by (A) radiation; (B) chemotherapy; (C) surgery; (D) bone metastasis; (E) brain metastasis; (F) liver metastasis.

Abbreviation: LCNEC, pulmonary large-cell neuroendocrine carcinoma.

rigorous inclusion criteria, exclusion criteria, and comprehensive variables, the purpose of this study was to assess prognostic factors for 1-, 3-, and 5-year CSS and construct an accurate nomogram for predicting prognosis in patients with LCNEC.

Fourteen independent prognostic factors have been identified for CSS in univariate Cox regression analysis, including gender, primary site, AJCC stage, $\mathrm{T}$ stage, $\mathrm{N}$ stage, $\mathrm{M}$ stage, surgery, radiation, chemotherapy, lymph nodes positive, bone metastasis, brain metastasis, liver metastasis and tumor size. In light of prior reports, our study manifested that LCNEC patients in a predominantly male population, and the mean age at diagnosis was $60-74$, only nearly $6 \%$ of patients were below 50 years old. Most of the primary lesion takes place in upper lobe $(60.9 \%)$ and lower lobe $(26.8 \%)$, this result was identical to previous SEER database based LCNEC studies and unraveled the characteristics of LCNEC. ${ }^{21-23}$

In the present study, the 3-year cumulative CSS probability were $72 \%, 71 \%, 40 \%, 39 \%, 25 \%, 15 \%$ and $3 \%$ for AJCC stages IA, IB, IIA, IIB, IIIA, IIIB and IV, Stage III and IV LCNEC have a markedly poorer prognosis compared with stage I and II tumors. Previous studies also showed that AJCC stage was the important factor for survival prognosis, but AJCC lung cancer staging system is not able to accurately predict clinical prognosis. ${ }^{11}$ Notably, T stage, $\mathrm{N}$ stage, and $\mathrm{M}$ stage were not included in the multivariate Cox analysis due to the mutual influence with AJCC stage. Remarkably, the degree of tumor histology and histological grade did not affect the patient survival, which was a departure from our expectation. ${ }^{24}$ 
Table 2 Univariate and Multivariate Analyses of CSS in the Training Cohort

\begin{tabular}{|c|c|c|c|}
\hline & \multicolumn{3}{|c|}{ Training Cohort } \\
\hline & $\begin{array}{c}\text { Univariate } \\
P \text { value }\end{array}$ & $\begin{array}{c}\text { Multivariate HR } \\
(95 \% \mathrm{Cl})\end{array}$ & $P$ value \\
\hline $\begin{array}{l}\text { Age } \\
\qquad \begin{array}{l}\leq 49 \\
50-59 \\
60-74 \\
\geq 75\end{array}\end{array}$ & 0.839 & & \\
\hline $\begin{array}{l}\text { Race } \\
\text { White } \\
\text { Black } \\
\text { Other races }\end{array}$ & 0.678 & & \\
\hline $\begin{array}{c}\text { Gender } \\
\text { Male } \\
\text { Female }\end{array}$ & $<0.001$ & $\begin{array}{c}\text { Ref. } \\
0.68(0.5 \mid-0.91)\end{array}$ & - \\
\hline $\begin{array}{l}\text { Primary Site } \\
\text { Main bronchus } \\
\text { Upper lobe } \\
\text { Middle lobe } \\
\text { Lower lobe } \\
\text { Overlapping } \\
\text { lesion of lung } \\
\text { Lung, NOS }\end{array}$ & 0.016 & $\begin{array}{c}\text { Ref. } \\
0.78(0.45-1.38) \\
1.19(0.55-2.55) \\
0.81(0.45-1.46) \\
1.35(0.42-4.32) \\
0.82(0.37-1.82)\end{array}$ & $\begin{array}{c}- \\
0.398 \\
0.658 \\
0.491 \\
0.617 \\
0.619\end{array}$ \\
\hline $\begin{array}{l}\text { Grade } \\
\text { I } \\
\text { II } \\
\text { III } \\
\text { IV }\end{array}$ & 0.676 & & \\
\hline $\begin{array}{l}\text { Laterality } \\
\text { Left } \\
\text { Right }\end{array}$ & 0.901 & & \\
\hline $\begin{array}{l}\text { AJCC Stage } \\
\text { IA } \\
\text { IB } \\
\text { IIA } \\
\text { IIB } \\
\text { IIIA } \\
\text { IIIB } \\
\text { IV }\end{array}$ & $<0.001$ & $\begin{array}{c}\text { Ref. } \\
1.31(0.60-2.83) \\
3.87(1.96-7.65) \\
4.40(2.15-9.00) \\
5.92(3.03-11.54) \\
7.38(3.25-16.75) \\
10.29(5.30-19.99)\end{array}$ & $\begin{array}{c}- \\
0.495 \\
<0.001 \\
<0.001 \\
<0.001 \\
<0.001 \\
<0.001\end{array}$ \\
\hline $\begin{array}{c}\text { T stage } \\
\text { T1 } \\
\text { T2 } \\
\text { T3 } \\
\text { T4 } \\
\text { Tx }\end{array}$ & $<0.001$ & NA & NA \\
\hline $\begin{array}{c}\text { N stage } \\
\text { NI } \\
\text { N2 }\end{array}$ & $<0.001$ & NA & NA \\
\hline
\end{tabular}

(Continued)
Table 2 (Continued).

\begin{tabular}{|c|c|c|c|}
\hline & \multicolumn{3}{|c|}{ Training Cohort } \\
\hline & $\begin{array}{c}\text { Univariate } \\
P \text { value }\end{array}$ & $\begin{array}{l}\text { Multivariate HR } \\
(95 \% \mathrm{Cl})\end{array}$ & $P$ value \\
\hline $\begin{array}{l}\text { N3 } \\
\text { N4 } \\
\text { Nx }\end{array}$ & & & \\
\hline $\begin{array}{c}\text { M stage } \\
\text { Mo } \\
\text { Mla } \\
\text { MIb }\end{array}$ & $<0.001$ & NA & NA \\
\hline $\begin{array}{l}\text { Surgery } \\
\text { None } \\
\text { Laser ablation/ } \\
\text { cryosurgery } \\
\text { Pulmonary } \\
\text { lobectomy } \\
\text { Pneumonectomy }\end{array}$ & $<0.001$ & $\begin{array}{c}\text { Ref. } \\
6.23(0.77-50.69) \\
0.46(0.25-0.82) \\
0.36(0.14-0.91)\end{array}$ & $\begin{array}{c}- \\
0.087 \\
<0.001 \\
0.030\end{array}$ \\
\hline $\begin{array}{l}\text { Radiation } \\
\text { sequence with } \\
\text { surgery } \\
\text { None } \\
\text { Intraoperative } \\
\text { radiation } \\
\text { Radiation after } \\
\text { surgery } \\
\text { Radiation prior } \\
\text { to surgery }\end{array}$ & 0.252 & & \\
\hline $\begin{array}{l}\text { Radiation } \\
\text { Yes } \\
\text { No/unknown }\end{array}$ & $<0.001$ & $\begin{array}{c}\text { Ref. } \\
\text { I.26(0.89-I.80) }\end{array}$ & $\begin{array}{c}- \\
0.183\end{array}$ \\
\hline $\begin{array}{l}\text { Chemotherapy } \\
\text { Yes } \\
\text { No/unknown }\end{array}$ & 0.003 & $\begin{array}{c}\text { Ref. } \\
2.39(1.76-3.26)\end{array}$ & $<-$ \\
\hline $\begin{array}{l}\text { LN Positive } \\
\text { Negative/ } \\
\text { unknown } \\
\text { Positive }\end{array}$ & $<0.001$ & $\begin{array}{c}\text { Ref. } \\
\text { I.09(0.74-1.62) }\end{array}$ & $\begin{array}{c}- \\
0.652\end{array}$ \\
\hline $\begin{array}{l}\text { Bone metastasis } \\
\text { Yes } \\
\text { No }\end{array}$ & $<0.001$ & $\begin{array}{c}\text { Ref. } \\
0.78(0.53-1.17)\end{array}$ & $\begin{array}{c}- \\
0.229\end{array}$ \\
\hline $\begin{array}{l}\text { Brain metastasis } \\
\text { Yes } \\
\text { No }\end{array}$ & $<0.001$ & $\begin{array}{c}\text { Ref. } \\
0.56(0.37-0.85)\end{array}$ & $\begin{array}{c}- \\
0.006\end{array}$ \\
\hline $\begin{array}{l}\text { Liver metastasis } \\
\text { Yes } \\
\text { No }\end{array}$ & $<0.001$ & $\begin{array}{c}\text { Ref. } \\
\text { I.36(0.87-2.08) }\end{array}$ & $\begin{array}{c}- \\
0.160\end{array}$ \\
\hline
\end{tabular}


Table 2 (Continued).

\begin{tabular}{|l|c|c|c|}
\hline \multirow{2}{*}{} & \multicolumn{3}{|c|}{ Training Cohort } \\
\cline { 2 - 4 } & $\begin{array}{c}\text { Univariate } \\
\text { P value }\end{array}$ & $\begin{array}{c}\text { Multivariate HR } \\
\mathbf{( 9 5 \% ~ C l )}\end{array}$ & P value \\
\hline Tumor size & $<0.001$ & & \\
$\leq 30$ & & Ref. & - \\
$31-50$ & & $0.96(0.67-1.39)$ & 0.848 \\
$51-70$ & & $1.05(0.69-1.59)$ & 0.819 \\
$>70$ & & $1.10(0.73-1.65)$ & 0.641 \\
\hline
\end{tabular}

Note: The bold values represent statistical significance.

Abbreviations: AJCC, American Joint Commission on Cancer; LN, lymph node; CSS, cancer-specific survival; NA, not applicable.

Our study confirms the predictive value of surgery and chemotherapy for prognosis in patients with LCNEC. Surgical management is recommended in early-stage patients, postoperative adjuvant chemotherapy can improve overall survival, ${ }^{25}$ however, comparative data between the different type of surgical procedures remain scant. Chemotherapy is the main treatment for advanced patients, including NSCLC chemotherapy regimens (platinum-based combined gemcitabine, docetaxel, paclitaxel, vinorelbine or pemetrexed) and small cell lung carcinoma (SCLC) chemotherapy regimens (etoposide-based chemotherapy). ${ }^{26-29}$ While radiotherapy has no obvious effect on prognosis and the data of immunotherapy is lacking in SEER database. Of note, the CSS curves showed that patients with radiotherapy or chemotherapy had obviously worse survival outcomes, which were different from most other studies. For instance, a recent study by Michael May et al indicate that radiation therapy offers significant benefit in stage I disease and possibly in stage II disease in patients who are not candidates for surgery or prefer nonoperative management. ${ }^{30}$ This is probably because this analysis based on treatment is highly biased due to the patient selection and confounders, patients with better prognostic expectations will often receive more active antitumor treatment, and have better survival.

Different metastatic sites can have keystone effects on survival and prognosis. Bone, brain and liver are the predominant metastatic site for LCNEC, and the incidence of brain metastases constitute the highest proportion. ${ }^{31,32}$ In the present study, the 1 year and 3 years cumulative CSS probability were $19 \%$ and $2 \%$. Therefore, we should give more focus to management of brain metastases, prophylactic cerebral irradiation (PCI) may decrease the risk of relapse and prolong overall survival.

Previous researchers have constructed nomograms for predicting OS in patients with LCNEC. However, this is the first time that CSS-prediction nomogram was established.

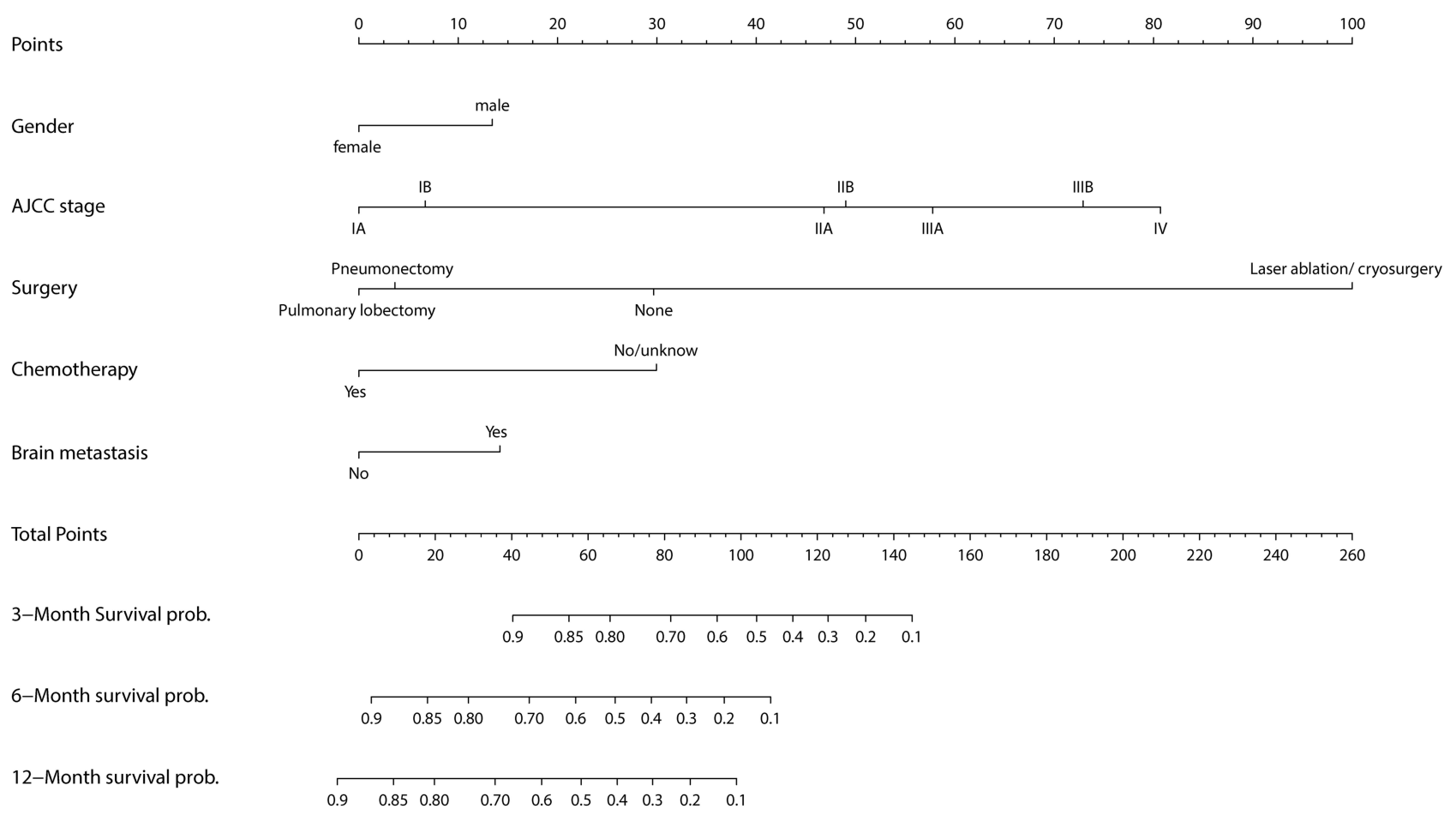

Figure 4 Nomogram for predicting I-, 3-, and 5-year CSS in LCNEC patients.

Abbreviations: AJCC, American Joint Commission on Cancer; CSS, cancer-specific survival; LCNEC, pulmonary large-cell neuroendocrine carcinoma. 
A

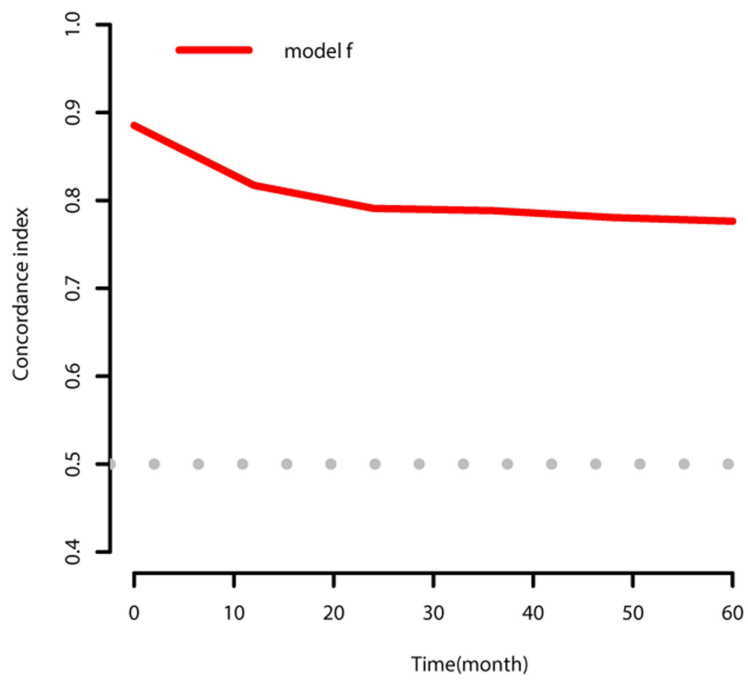

B

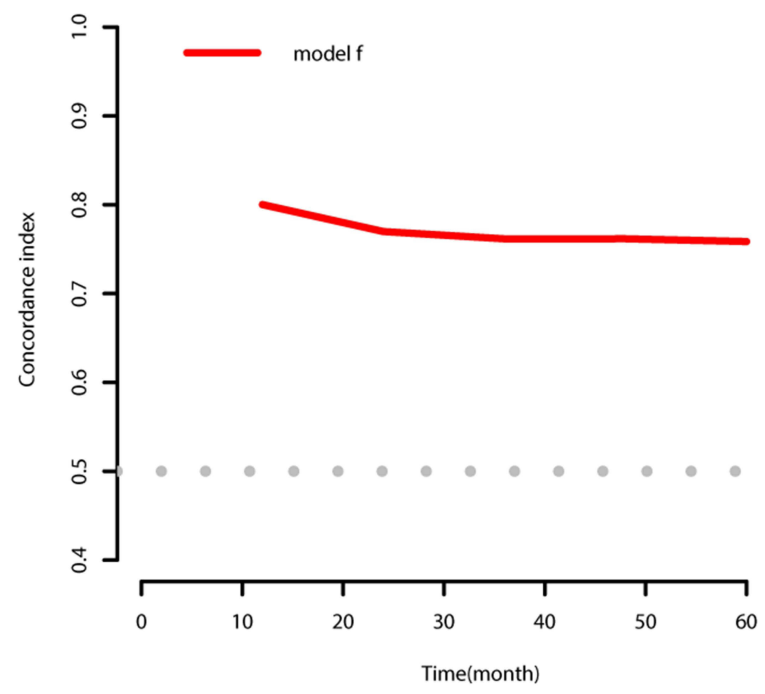

Figure 5 The concordance index of training cohorts $(\mathbf{A})$ and validation cohorts $(\mathbf{B})$.

A

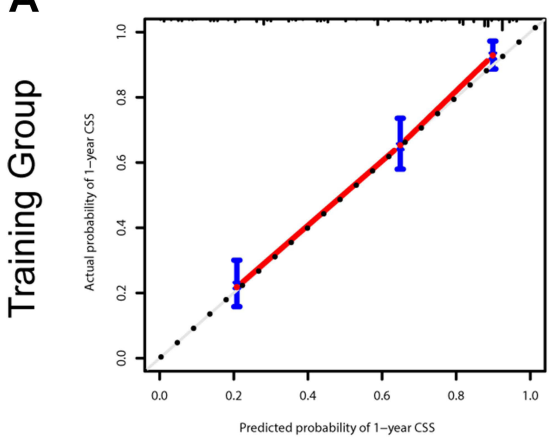

B

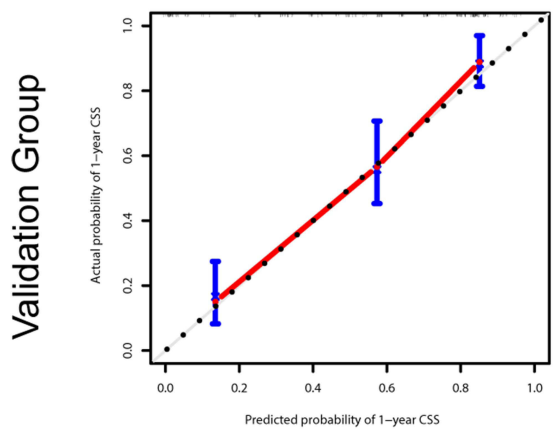

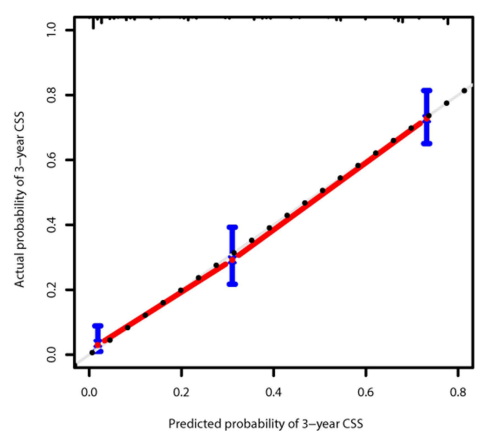
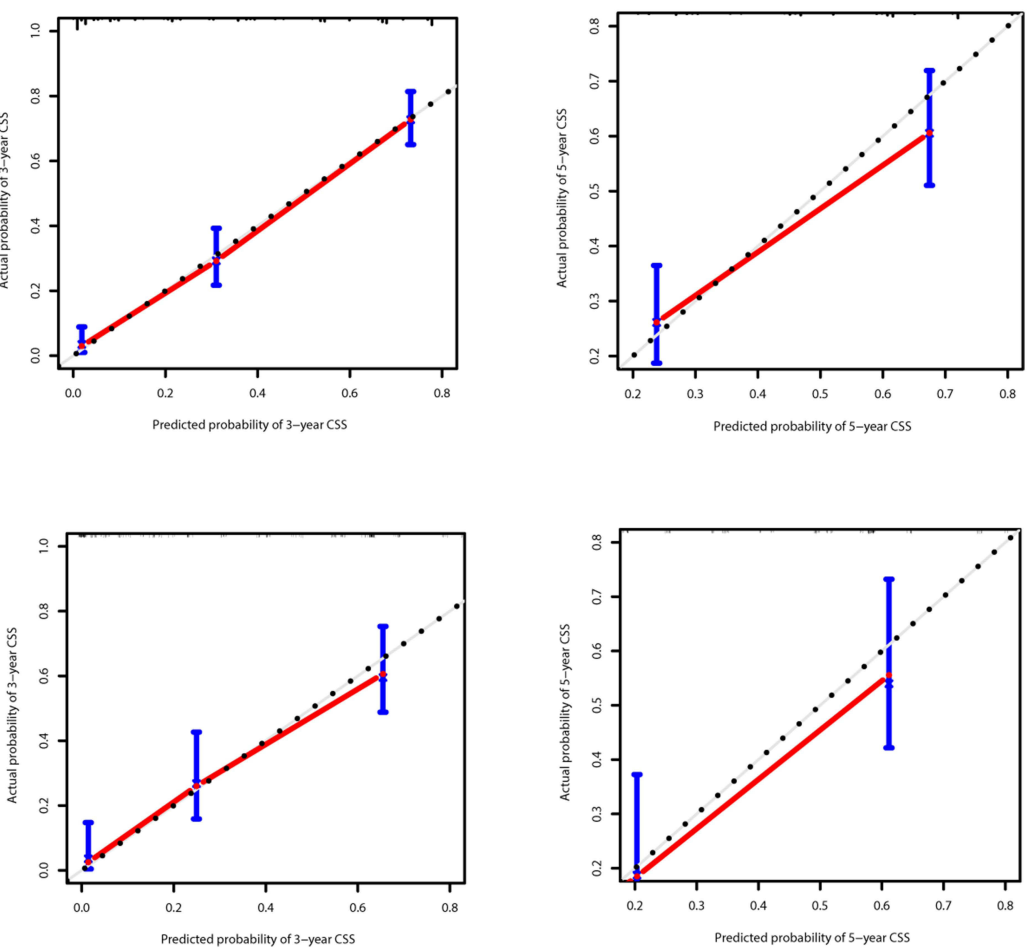

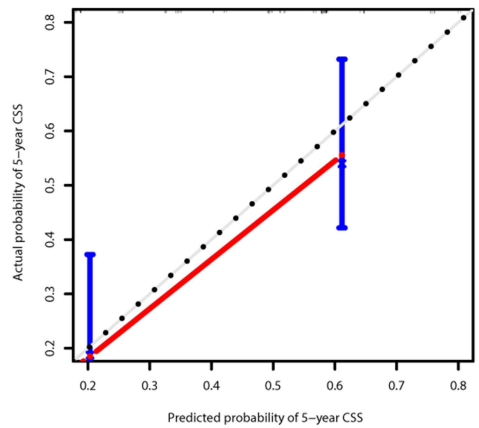

Figure 6 Calibration curves for the nomogram in the training and validation cohorts. I-, 3-, and 5-year calibration curves (A) for the CSS nomogram in the training cohort of patients with LCNEC (bootstrap = 1000 repetitions). I-, 3-, and 5-year calibration curves (B) for the CSS nomogram in the validation cohort of patients with LCNEC (bootstrap $=1000$ repetitions).

Abbreviations: LCNEC, pulmonary large-cell neuroendocrine carcinoma; CSS, cancer-specific survival.

Besides, In the present study, we followed a more comprehensive and rigorous approach. We have established a strict and reasonable inclusion criteria and exclusion criteria that aims to ensure the data are complete and accurate. After setting up the nomogram, we have used a variety of approaches to validate this model. In our study, the C-Index 

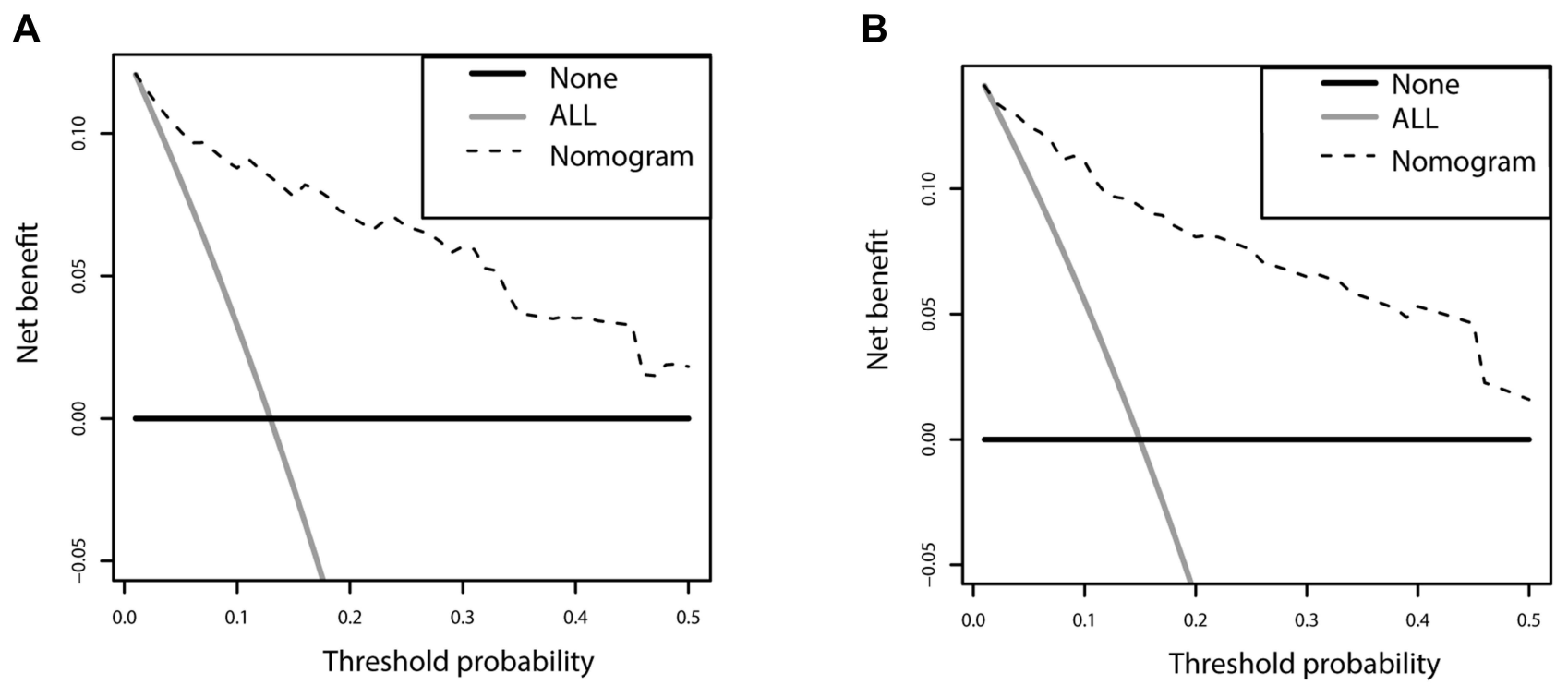

Figure 7 DCA curves of the nomogram for CSS in the training and validation cohorts. DCA curves of the nomogram for CSS in both the training cohort (A) and validation cohort (B).

Abbreviations: DCA, decision curve analysis; CSS, cancer-specific survival.

of the training and validation cohorts were both higher than 0.8 , achieving a better prediction performance. The calibration curve showed that the nomogram predictions are in a good agreement with the actual survival. The clinical utility of the nomogram was further confirmed by DCA curve. Thus, it is our belief that, our nomogram can provide clinicians with good CSS predictions for individual LCNEC patients.

However, our study also presented some limitations. First, this study was a retrospective study which was flawed due to the selection bias. For example, patients who received surgery had better survival because metastatic patients are not taken to surgery. Similarly, the selection bias also exists for immunotherapy, which was used in further lines for patients that have poor response history. Besides, In the design of the study, patients with history of more lines of treatment history. Second, this model was based on the data that were extracted from SEER database, thus the data in Asians are lacking. Third, a paucity of relevant data about some important factors exists in the SEER. For example, details on the treatment options are not mentioned. Therefore, further high-quality clinical research into the assessment of survival outcomes for LCNEC patients is still needed.

\section{Conclusion}

The nomogram proposed in this study may objectively and accurately predict 1-, 3-, and 5-year CSS of patients with LCNEC. The nomograms performed well in both training and validation cohorts. It might help clinicians to predict the prognosis of these patients and guide personalized treatment. However, since the present study faces some limitations, further clinical studies with larger sample sizes are needed to fully determine the best treatment options and more accurately predict the prognosis.

\section{Abbreviations}

LCNEC, large-cell neuroendocrine carcinoma; CSS, cancer-specific survival; OS, overall survival; SEER, Surveillance, Epidemiology, and End Results; NCI, National Cancer Institute; NSCLC, non-small cell lung carcinoma; C-Index, concordance index; DCA, decision curve analysis; SCLC, small cell lung carcinoma.

\section{Data Sharing Statement}

Publicly available datasets were analyzed in this study. This data can be found here: https://seer.cancer.gov/.

\section{Ethics Approval and Informed Consent}

Our data from SEER database. This is a public research database. Due to the informed patient consent in SEER database is not requires, it considered that ethical approval is not needed. Considering that all data used in the study are from public databases, Institutional Ethics Committee of Guangdong Provincial Hospital of Chinese Medicine have exempted this study from approval. 


\section{Author Contributions}

All authors made a significant contribution to the work reported, whether that is in the conception, study design, execution, acquisition of data, analysis and interpretation, or in all these areas; took part in drafting, revising or critically reviewing the article; gave final approval of the version to be published; have agreed on the journal to which the article has been submitted; and agree to be accountable for all aspects of the work.

\section{Funding}

This work was supported by the National Natural Science Foundation of China (NSFC 81904004), the Science and Technology Planning Project of Guangdong Province (No. 2017B030314166), and the 2020 Guangdong Provincial Science and Technology Innovation Strategy Special Fund (Guangdong-Hong Kong-Macau Joint Lab, No: 2020B1212030006).

\section{Disclosure}

The authors declare no competing interests.

\section{References}

1. Sung H, Ferlay J, Siegel RL, et al. Global cancer statistics 2020: globocan estimates of incidence and mortality worldwide for 36 cancers in 185 countries. CA Cancer J Clin. 2021;71:209-249.

2. Battafarano RJ, Fernandez FG, Ritter J, et al. Large cell neuroendocrine carcinoma: an aggressive form of non-small cell lung cancer. $J$ Thorac Cardiovasc Surg. 2005;130:166-172.

3. Lázaro S, Pérez-Crespo M, Lorz C, et al. Differential development of large-cell neuroendocrine or small-cell lung carcinoma upon inactivation of 4 tumor suppressor genes. Proc Natl Acad Sci. 2019;116:22300-22306.

4. Fasano M, Della Corte CM, Papaccio F, Ciardiello F, Morgillo F. Pulmonary large-cell neuroendocrine carcinoma: from epidemiology to therapy. $J$ Thorac Oncol. 2015;10:1133-1141.

5. Raman V, Jawitz OK, Yang C-FJ, et al. Adjuvant therapy for patients with early large cell lung neuroendocrine cancer: a national analysis. Ann Thorac Surg. 2019;108:377-383.

6. Lo H, Abel S, Finley G, Weksler B, Colonias A, Wegner RE. Surgical resection versus stereotactic body radiation therapy in early stage bronchopulmonary large cell neuroendocrine carcinoma. Thoracic Cancer. 2020;11:305-310.

7. Balachandran VP, Gonen M, Smith JJ, DeMatteo RP. Nomograms in oncology: more than meets the eye. Lancet Oncol. 2015;16:e173e180.

8. Zeng Y, Mayne N, Yang C-FJ, et al. A nomogram for predicting cancer-specific survival of TNM 8th edition stage I non-small-cell lung cancer. Ann Surg Oncol. 2019;26:2053-2062.

9. Xiang G-H, Zhu -J-J, Ke C-R, et al. Nomograms predict overall survival and cancer-specific survival in patients with fibrosarcoma: a seer-based study. J Oncol. 2020;2020. doi:10.1155/2020/8284931

10. Wang F, Zhang H, Wen J, et al. Nomograms forecasting long-term overall and cancer-specific survival of patients with oral squamous cell carcinoma. Cancer Med. 2018;7:943-952.
11. He Y, Liu H, Wang S, Chen Y. Prognostic nomogram predicts overall survival in pulmonary large cell neuroendocrine carcinoma. PLoS One. 2019;14:e223275.

12. Wright DB, Horry R, Skagerberg EM. Functions for traditional and multilevel approaches to signal detection theory. Behav Res Methods. 2009;41:257-267.

13. Suresh K. An overview of randomization techniques: an unbiased assessment of outcome in clinical research. J Hum Reprod Sci. 2011;4:8.

14. Benitez-Parejo N, Del Águila MR, Pérez-Vicente S. Survival analysis and cox regression. Allergol Immunopathol. 2011;39:362-373.

15. Zhang Z, Kattan MW. Drawing nomograms with r: applications to categorical outcome and survival data. Ann Transl Med. 2017;5:211

16. Kattan MW, Gerds TA. A framework for the evaluation of statistical prediction models. Chest. 2020;158:S29-S38.

17. Vickers AJ, Elkin EB. Decision curve analysis: a novel method for evaluating prediction models. Med Decis Making. 2006;26:565-574.

18. Deng C, Wu S-G, Y T. Lung large cell neuroendocrine carcinoma: an analysis of patients from the surveillance, epidemiology, and end-results (seer) database. Med Sci Monit. 2019;25:3636.

19. Gu J, Gong D, Wang Y, et al. The demographic and treatment options for patients with large cell neuroendocrine carcinoma of the lung. Cancer Med. 2019;8:2979-2993.

20. Kinslow CJ, May MS, Saqi A, et al. Large-cell neuroendocrine carcinoma of the lung: a population-based study. Clin Lung Cancer. 2020;21:e99-e113.

21. Cao L, Li Z-W, Wang M, Zhang T-T, Bao B, Liu Y-P Clinicopathological characteristics, treatment and survival of pulmonary large cell neuroendocrine carcinoma: a seer population-based study. PeerJ. 2019;7:e6539.

22. Jiang Y, Lei C, Zhang X, Cui Y, Che K, Shen H. Double-edged role of radiotherapy in patients with pulmonary large-cell neuroendocrine carcinoma. J Cancer. 2019;10:6422.

23. Zhang J-T, Li Y, Yan L-X, et al. Disparity in clinical outcomes between pure and combined pulmonary large-cell neuroendocrine carcinoma: a multi-center retrospective study. Lung Cancer. 2020;139:118-123.

24. Iyoda A, Hiroshima K, Moriya Y, et al. Prognostic impact of large cell neuroendocrine histology in patients with pathologic stage IA pulmonary non-small cell carcinoma. $J$ Thorac Cardiovasc Surg. 2006;132:312-315.

25. Shen Y, Hu F, Li C, et al. Clinical features and outcomes analysis of surgical resected pulmonary large-cell neuroendocrine carcinoma with adjuvant chemotherapy. Front Oncol. 2020;10:2659.

26. Masters GA, Temin S, Azzoli CG, et al. Systemic therapy for stage iv non-small-cell lung cancer: American society of clinical oncology clinical practice guideline update. J Clin Oncol. 2015;33:3488.

27. Le Treut J, Sault M, Lena H, et al. Multicentre Phase II study of cisplatinetoposide chemotherapy for advanced large-cell neuroendocrine lung carcinoma: the gfpc 0302 study. Ann Oncol. 2013;24:1548-1552.

28. Niho S, Kenmotsu H, Sekine I, et al. Combination chemotherapy with irinotecan and cisplatin for large-cell neuroendocrine carcinoma of the lung: a multicenter phase ii study. J Thorac Oncol. 2013;8:980-984.

29. Rossi A, Di Maio M, Chiodini P, et al. Carboplatin-or cisplatin-based chemotherapy in first-line treatment of small-cell lung cancer: the cocis meta-analysis of individual patient data. $J$ Clin Oncol. 2012;30:1692-1698. doi:10.1200/JCO.2011.40.4905

30. May MS, Kinslow CJ, Adams C, et al. Outcomes for localized treatment of large cell neuroendocrine carcinoma of the lung in the United States. Transl Lung Cancer Res. 2021;10:71.

31. Trikalinos NA, Tan BR, Amin M, Liu J, Govindan R, Morgensztern D. Effect of metastatic site on survival in patients with neuroendocrine neoplasms (nens). An analysis of seer data from 2010 to 2014. BMC Endocr Disord. 2020;20:1-10.

32. Zhao Y, Castonguay M, Wilke D, et al. Treatment outcomes and incidence of brain metastases in pulmonary large cell neuroendocrine carcinoma. Curr Probl Cancer. 2019;43:54-65. 


\section{Publish your work in this journal}

The International Journal of General Medicine is an international, peer-reviewed open-access journal that focuses on general and internal medicine, pathogenesis, epidemiology, diagnosis, monitoring and treatment protocols. The journal is characterized by the rapid reporting of reviews, original research and clinical studies across all disease areas. The manuscript management system is completely online and includes a very quick and fair peer-review system, which is all easy to use. Visit http://www.dovepress.com/ testimonials.php to read real quotes from published authors. 